\title{
Failure of Composite Laminates Containing Pin Loaded Holes-Method of Solution
}

\author{
FU-KUO CHANG AND RICHARD A. SCOTT \\ Department of Mechanical Engineering and Applied Mechanics \\ The University of Michigan, Ann Arbor, Michigan 48109
}

AND

GEORGE S. SPRINGER

Department of Aeronautics and Astronautics

Stanford University, Stanford, California 94305

(Received November 11, 1983)

(Revised February 23, 1984)

\begin{abstract}
A method is presented for predicting the failure strength and the failure mode of fiber reinforced composite laminates containing one or two pin loaded holes. The method involves two steps. First, the stress distribution in the laminate is calculated by the use of a finite element method. Second, the failure load and failure mode are predicted by means of a proposed failure hypothesis together with the Yamada-Sun failure criterion. A computer code was developed which can be used to calculate the maximum load and the mode of failure of laminates with different ply orientations, different material properties, and different geometries. Tests were also conducted measuring the failure strengths and failure modes of Fiberite $\mathrm{T} 300 / 1034-\mathrm{C}$ laminates containing a pin-loaded hole or two pin-loaded holes in parallel or in series. Comparisons were made between the data and the results of the model. Good agreement was found between the analytical and the experimental results.
\end{abstract}

\section{INTRODUCTION}

TN STRUCTURAL APPLICATIONS COMPOSITES ARE GENERALLY FASTENED leither to composites or to metals by mechanical means. Therefore, to utilize the full potential of composite materials as structural elements, the strength and failure of mechanically fastened joints in laminated composites must be understood.

Owing to the significance of the problem, several investigators have developed analytical procedures for calculating the strength of bolted joints 
in composite materials. Among the recent studies are those of Waszczak and Cruse [1], Oplinger and Gandhi [2,3], Agarwal [4], Soni [5], Garbo and Ogonowski [6], York, Wilson, and Pipes [7,8], and Collings [9]. The results of these investigations apply only to joints containing a single hole, and, with the exception of Agarwal's method, none of the previous methods can predict the mode of failure. Furthermore, as will be discussed in Section 7, the previous methods provide conservative results and underestimate the failure strength, often by as much as 50 percent.

The major objective of the investigation was, therefore, to develop a method which a) can be used to estimate both the failure strength and the failure mode of pin-loaded holes in composites, b) applies to laminates containing either one or two pin-loaded holes, c) provide results with as good or better accuracy than the existing analytical methods and, d) can be used in the design of mechanically-fastened composite joints.

An analysis applicable to composite laminates containing a single hole was described in References [10,11]. In this paper, this analysis is extended to laminates containing two pin load holes placed either in parallel or in series. In addition, data are presented for validating the analytical results.

\section{PROBLEM STATEMENT}

Consider a plate (length $\mathrm{L}$, width $\mathrm{W}$, thickness $\mathrm{H}$ ) made of $\mathrm{N}$ fiberreinforced unidirectional plies. The ply orientation is arbitrary, but must be symmetric with respect to the $x_{3}=0$ plane. Perfect bonding between each ply is assumed.

Three types of problems are analyzed (see Figure 1): a) A single hole of diameter $\mathrm{D}$ is located along the centerline of the plate; b) Two holes of diameter $\mathbf{D}$ are located at equal distances from the centerline of the plate (two holes in parallel); c) Two holes of diameter $\mathrm{D}$ are located along the centerline of the plate (two holes in series). A rigid pin, supported outside the plate, is inserted into each hole.

A uniform tensile load $P$ is applied to the lower edge of the plate and a uniform tensile load $\mathrm{P}_{\mathbf{2}}$ (referred to as the "by-pass" load) is applied to the upper edge.

It is desired to find:

1) the maximum (failure) load $\left(P_{M}\right)$ that can be applied before the joint fails, and

2) the mode of failure.

Point 2 refers to the fact that, according to experimental evidence, mechanically-fastened joints under tensile loads generally fail in three basic modes, referred to as tension mode, shearout mode, and bearing mode. The type of damage resulting from each of these modes is illustrated in Figure 2. The objective, listed in point 2 above, is to determine which of these modes will most be responsible for the failure.

The calculation proceeds in three steps. For a given geometry and load: 

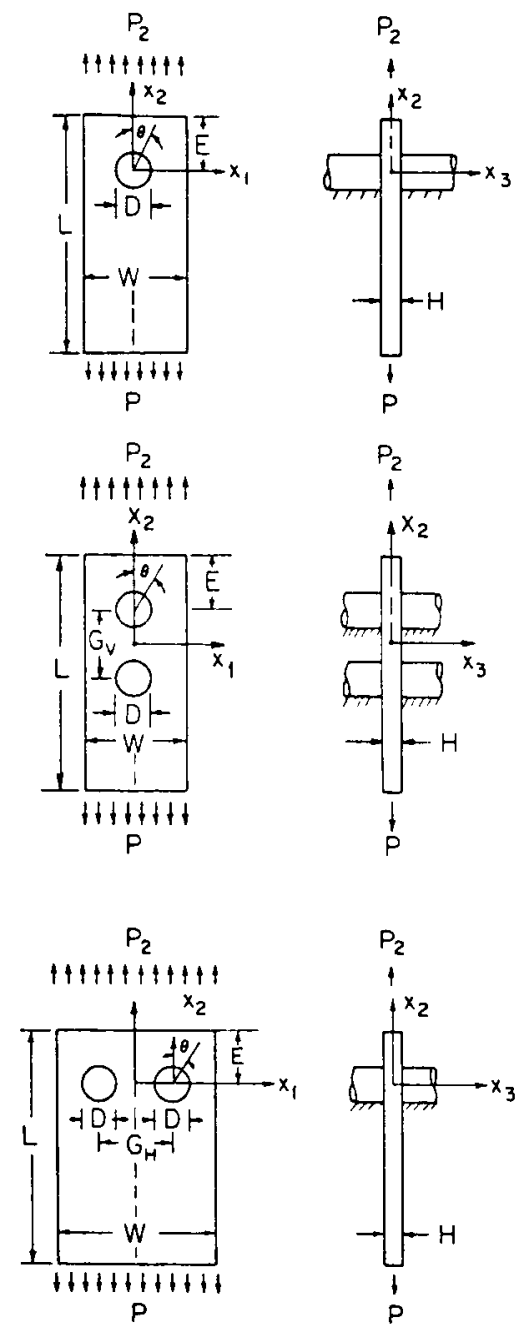

Figure 1. Descriptions of the problem. Top: single hole model; middle: two holes in series; bottom two holes in parallel.

1) the stress and strain distributions around the hole are calculated,

2) the maximum (failure) load is predicted,

3) the mode of failure is determined.

\section{STRESS ANALYSIS}

The calculation of stresses raises the issue of whether a two or threedimensional stress analysis is required. The applied loads are parallel to the 

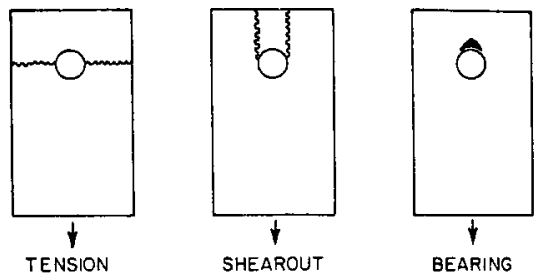

Figure 2. Illustration of the three basic failure modes.

plate (in-plane loading) and are symmetric with respect to the centerline. Hence, the loads cannot create bending moments about either the $\mathrm{x}_{1}, \mathrm{x}_{2}$, or $\mathrm{x}_{3}$ axes. Moreover, for symmetric laminates, in-plane loading and bending effects are uncoupled. Transverse forces, (i.e., forces in the $x_{3}$ direction) are not applied, and transverse displacement of the laminate is not taken into account. For example, a washer on each side of the laminate, supported by a lightly-tightened ("finger-tight") bolt in the hole, would ensure that there is little transverse displacement, and that a condition of two-dimensionality is reasonable [12]. If tests were to show that the stacking sequence did not affect the failure strength and the failure mode, then a two-dimensional stress analysis would suffice. Existing experimental evidence indicates that the stacking sequence is important only when a) the laminate is narrow (and edge effects are not negligible [13]), or b) the laminate is unrestrained laterally [14]. However, even when the stacking sequence affects the results, it seems to affect the failure strength by only 10 to 20 percent [13-17]. Furthermore, the failure strength and the failure mode seem unaffected by the stacking sequence when there is a slight lateral constraint on the laminate, such as provided by lightly tightened (finger-tight) bolts $[12,18,19]$.

For these reasons, a two-dimensional stress analysis was chosen for the present work. As will be demonstrated in Section 7, this analysis provides a useful estimate of the failure strength and the failure mode of loaded holes. In addition to being reasonably accurate, the two-dimensional analysis adopted here also provides a simple and inexpensive means for calculating failure strengths and failure modes, making it an attractive design aid.

\section{Governing Equations}

The stresses in the laminate are calculated on the basis of the theory of anisotropic elasticity and classical-lamination plate theory. Accordingly, in the analysis, planes are taken to remain planes, the strain across the thickness is taken to be constant $\left[\varepsilon_{\mathrm{ij}}=\mathrm{f}\left(\mathrm{x}_{1}, \mathrm{x}_{2}\right)\right]$, and only in-plane stresses are considered $\left(o_{13}=\sigma_{23}=\sigma_{33}=0\right)$. Under these conditions, in the absence of body forces, the condition of force equilibrium can be expressed as [20]:

$$
\begin{aligned}
& \partial \sigma_{11} / \partial x_{1}+\partial \sigma_{12} / \partial x_{2}=0 \\
& \partial \sigma_{21} / \partial x_{1}+\partial \sigma_{22} / \partial x_{2}=0
\end{aligned}
$$


In index notation Equation (1) becomes

$$
\sigma_{i j, j}=0, i, j=1,2
$$

Now consider an elastic laminate of volume $V_{o}$ containing a single pinloaded hole or two pin-loaded holes, as shown in Figure 3. Loads are applied over the surface area $A_{L}$. The displacements along the surface area $A_{R}$ are restricted in a manner described subsequently. The surface area $A_{F}$ is free of applied stress.

The total surface area is

$$
A=A_{L}+A_{R}+A_{F}
$$

Let us denote by $\bar{u}_{i}$ any arbitrary displacement inside the body. $\bar{u}_{i}$ is a test function. The only requirement is that $\bar{u}_{i}$ be continuous and differentiable. In addition, along the $A_{R}$ surface, the components of $\bar{u}_{i}$ normal to the surface must be zero. By multiplying Equation (2) by $\bar{u}_{i}$ and by taking the volume integral of the resulting expression, we obtain

$$
\iiint_{V_{0} \sigma_{i j, j}} \bar{u}_{i} d V=0
$$

By employing the identity

$$
\sigma_{i j, j} \bar{u}_{i}=\left(\sigma_{i j} \bar{u}_{i}\right)_{, j}-\sigma_{i j} \bar{u}_{i, j}
$$

and by utilizing Gauss' theorem, Equation (4) may be written as

$$
\iint_{A} \sigma_{i j} n_{j} \bar{u}_{i} d A-\iiint_{V_{o}} \sigma_{i j} \bar{u}_{i, j} d V=0
$$
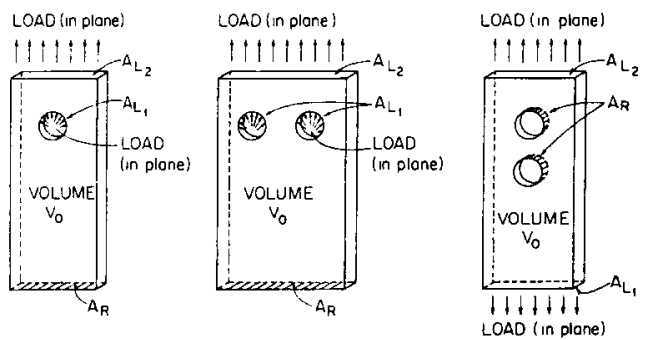

TOTAL SURFACE A

LOADED SURFACE; $A_{L}=A_{L_{1}}+A_{L_{2}}$

RESTRICTED SURFACE $A_{R}$

Figure 3. Elastic laminates with one hole (left), two holes in parallel (middle), and two holes in series (right). 
where $n_{j}$ is the unit vector normal to the surface. By utilizing Equation (3), Equation (6) can be expressed as

$\iint_{A_{L}} \sigma_{i j} n_{j} \bar{u}_{i} d A+\iint_{A_{R}} \sigma_{i j} n_{j} \bar{u}_{i} d A+\iint_{A_{F}} \sigma_{i j} n_{j} \bar{u}_{i} d A=\iiint_{V_{o}} \sigma_{i j} \bar{u}_{i j} d V$

On the free surface $A_{F}$ the stresses are zero. This condition gives

$$
\iint_{A_{F}} \sigma_{i j} n_{j} \bar{u}_{i} d A=0
$$

The forces per unit area (surface traction) at each point of the surface area $A_{L}$ are [20]:

$$
T_{i}=\sigma_{i j} n_{j}
$$

Equations (7)-(9) yield

$$
\iint_{A_{L}} T_{i} \bar{u}_{i} d A+\iint_{A_{R}} \sigma_{i j} n_{j} \bar{u}_{i} d A=\iiint_{V_{0}} o_{i j} \bar{u}_{i j} d V
$$

The stresses are related to the displacements through the stress-strain relationships, which for an elastic body are [20]

$$
\sigma_{i j}=E_{i j k l} \varepsilon_{k l}
$$

The subscripts $k$ and $\ell$ may take on the values of 1 or 2 . In order to reduce the analysis from three dimensions to two dimensions, the reduced modulus $E_{m n}$ is introduced

$$
E_{i k \ell}=E_{m n}=\sum_{p=1}^{N}\left(h^{p} / H\right) \bar{Q}_{m n}^{p}
$$

where $h^{p}$ is the thickness of the p-th ply, and $[\bar{Q}]^{p}$ is the transformed reduced stiffness matrix for the P-th ply $[11,21]$. The subscripts $i, j, k$, and $\ell$ are related to $m$ and $n$ as follows

$$
\begin{aligned}
& i=j=1 \rightarrow m=1 k=\ell=1 \rightarrow n=1 \\
& i=j=2 \rightarrow m=2 k=\ell=2 \rightarrow n=2 \\
& i \neq j \quad \rightarrow m=3 k \neq l \quad \rightarrow n=3
\end{aligned}
$$

Note that these reduced moduli are constant and are independent of the thickness of the laminate. The strains are related to the displacements $u_{j}$ by the expressions

$$
\varepsilon_{k l}=(1 / 2)\left(\partial u_{k} / \partial x_{l}+\partial u_{l} / \partial x_{k}\right)
$$


By combining Equations (10-14) we obtain

$$
\iiint_{V_{0}} E_{i j k \ell} \bar{u}_{i, j} u_{k, l} d V=\iint_{A_{L}} T_{i} \bar{u}_{i} d A+\iint_{A_{R} \sigma_{j} n_{j} \bar{u}_{i} d A}
$$

The displacements and, consequently, the strains are constant across the laminate. Hence the stresses, as defined by Equation (11), are also constant across the laminate. However, the stresses with respect to the ply coordinates $\mathrm{x}, \mathrm{y}$ are taken to vary from ply-to-ply, and are given by

$$
\left\{\begin{array}{c}
\sigma_{x}^{p} \\
\sigma^{p} \\
\sigma_{x y}^{p}
\end{array}\right\}=[T][\bar{Q}]^{p}\left\{\begin{array}{c}
\varepsilon_{1} \\
\varepsilon_{2} \\
\gamma_{12}
\end{array}\right\}
$$

where the subscripts $x$ and $y$ indicate directions parallel and normal to the fibers, respectively. The matrix $[T]$ is the coordinate transformation matrix, $[\bar{Q}]$ is the transformed reduced stiffness matrix [22] and $\gamma_{12}$ is engineering shear strain.

\section{Boundary Conditions-Single Hole and Two Holes in Parallel}

For problems involving a single hole and two holes in parallel, it is assumed that a portion of the surface of each hole is subjected to a surface traction $T_{i}^{*}$ (Figure 4). The parameter $T_{i}^{*}$ is related to the applied load. The spatial distribution of $T_{i}^{*}$ depends on the magnitude of the applied load, on the material properties, and on the geometry in a complex manner. It is difficult to determine the exact distribution of $T_{i}^{*}$ inside the hole [23-25]. To overcome this difficulty, a cosine normal load distribution was assumed. With this approximation, a force balance in the $x_{2}$ direction gives

$$
P=P_{2}+H \int_{-\pi / 2}^{\pi / 2}(D / 2) T_{x_{2}} \cos ^{2} \theta d \theta
$$
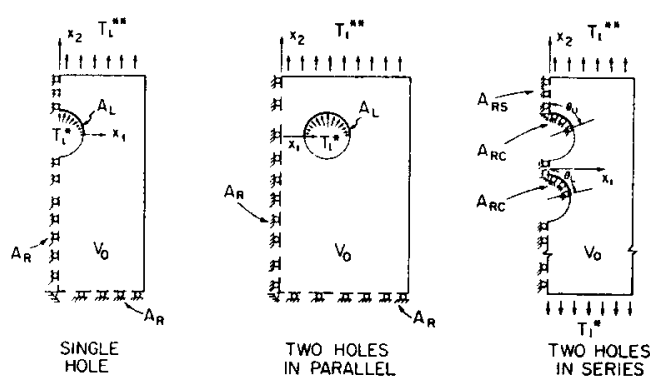

Figure 4. Configurations used in the finite element ca/culations. 
where $T_{x_{2}}$ is the normal stress at the hole surface at $\theta=0$. At any arbitrary angle $\theta(-\pi / 2 \leqslant \theta \leqslant \pi / 2)$, the stress normal to the surface has been assumed to be

$$
T_{i}^{*}=T_{x_{2}} n_{i} \cos \theta
$$

Solving Equation (17) for $T_{x_{2}}$ and substituting into Equation (18) gives

$$
T_{i}^{*}=-4 C\left(\left(P-P_{2}\right) / \pi D H\right) n_{i} \cos \theta
$$

where $P_{2}$ is the by-pass load which is a fraction $f$ of the total load $P$.

$$
P_{2}=f P
$$

The values of either $P$ and $P_{2}$ or $P$ and $f$ must be specified. Now the surface traction on $A_{L 1}$ can be written as

$$
T_{i}^{*}=-C(P(I-f) / \pi D H) n_{i} \cos \theta
$$

The surface traction on $A_{L 2}$ is

$$
T_{i}^{* *}=\left(P_{2} / H W\right) n_{i}=(f P / H W) n_{i}
$$

For a single hole $C$ is equal to 1 ; for two holes in parallel it is equal to $1 / 2$. The angle $\theta$ varies from $-\pi / 2$ to $\pi / 2$ in each hole. The angle $\theta$ is in the $x_{1}-x_{2}$ plane, and is measured clockwise from the $x_{2}$ axis (Figure 1). For isotropic materials, the cosine normal load distribution (Equation 21) was found to represent closely the actual load distribution [26]. Calculations performed by previous investigators also showed that, for composite materials, the stress distribution inside the body is insensitive to the assumed load distribution $[1,6,27]$. Therefore, Equation (21) should suffice for the purpose of the present analysis, which is to determine the overall strength of the joint.

Equations (1), (20), (21) and (22) give

$$
\begin{aligned}
& \iiint_{V_{o}} E_{i j k} \bar{u}_{i, j} u_{k, 1} d V=\iint_{A_{L 1}}-C(4 p(1-f) / \pi D H) n_{i} \bar{u}_{i} \cos \theta d A+ \\
& \iint_{A_{L 2}}(f p / H W) n_{i} \bar{u}_{i} d A+\iint_{A_{R}} \sigma_{i j} n_{j} \bar{u}_{i} d A
\end{aligned}
$$

We recall that $\bar{u}_{i}$ are functions that can be selected arbitrarily. The unknowns in Equation (23) are the displacements $u_{k}$. Once $u_{k}$ are known, the stresses at every point can be calculated from Equations (14) and (16).

Solutions to Equation (23) must be obtained subject to the following constraints: a) Along the symmetry axis and along the lower edge, displacements are allowed only in the direction tangential to the surface. These tangential displacements may occur freely without any restraints, b) The intersection of 
the symmetry axis and the lower edge must not move (i.e., the intersection in rigidly fixed).

The integral (Equation 23) over the $A_{R}$ surface now applies to the surfaces along the symmetry axis and along the lower edge (Figure 4). On these surfaces the normal component of the displacement and the tangential component of the surface traction are zero. Accordingly, we have

$$
\iint_{A_{R}} \sigma_{i j} n_{j} \bar{u}_{i} d A=0
$$

Equation (23) can now be simplied and becomes

$$
\begin{aligned}
& \iiint_{V_{o}} E_{y k \ell} \bar{u}_{1,} \mu_{k, l} d V=\iint_{A_{L 1}}-C(4 P(I-f) / \pi D H) n_{i} \bar{u}_{i} \cos \theta d A \\
& +\iint_{A_{L 2}}(f P / H W) n_{i} \bar{u}_{i} d A
\end{aligned}
$$

\section{Boundary Condition-Two Holes in Series}

For problems involving two holes in series the fraction of the load carried by each pin is unknown. To analyze the problem, it is assumed that a uniform load distribution is applied along the lower edge of the plate, and it is further assumed that a rigid pin is inside each hole. The assumption of the rigid pins implies that the normal displacements are zero along the contact surface (Figure 4). The extent of the contact surfaces are unknown and need to be determined.

The uniform load distribution on the $A_{L 1}$ surface is

$$
T_{i}^{*}=-(P / H W) n_{i}
$$

where $H$ and $W$ are the thickness and the width of the plate, respectively (Figure 1).

Equations (15), (22), (26) give

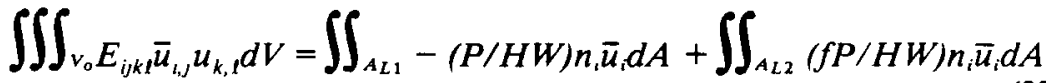

$$
\begin{aligned}
& +\iint_{A_{R} \sigma_{i j}} n_{j} \bar{u}_{i} d A
\end{aligned}
$$

As before, $\bar{u}_{i}$ can be selected arbitrarily but must satisfy the displacement boundary conditions. Hence, the unknowns in Equation (27) are the displacements $u_{k}$. The solution to Equation (27) must be obtained with the displacement $u_{k}$ subject to the following constraints:

a) Along the symmetry axis displacements are allowed only in the direction tangential to the surface (i.e., in the $x_{2}$ direction). This tangential displacement may occur freely.

b) The contacts between the rigid pins and the surfaces of the holes are assumed to be frictionless and are assumed to take place through arcs 
bounded by the angles $\theta_{\mathrm{U}}$ and $\theta_{\mathrm{L}}$ (Figure 4). Along these arcs the surface displacements can take place only in the direction tangential to the surface. Because of the assumption of frictionless contact, this displacement may occur freely.

c) The radial displacements at the intersections of the symmetry axis and the upper edge of each hole are zero (i.e., these intersections are rigidly fixed). This corresponds to the rigid supporting pins being fixed in space.

The integral over the $A_{R}$ area now applies to the symmetry axis and to contact surfaces. We express $A_{R}$ as the sum of two surfaces

$$
A_{R}=A_{R S}+A_{R C}
$$

$A_{R S}$ is the surface area along the symmetry axis and $A_{R C}$ is the total contact surface inside the upper and lower holes. Along the symmetry axis, the normal component of the displacement and the tangential component of surface traction are zero. Accordingly, we have

$$
\iint_{A_{R S} \sigma_{i j}} n_{j} \bar{u}_{i} d A=0
$$

Equation (27) gives

$$
\begin{aligned}
& \iiint_{v_{\sigma}} E_{i j k} \bar{u}_{i, j} u_{k, l} d v=\iint_{A_{L 1}}-(P / H W) n_{i} \bar{u}_{i} d A+ \\
& \iint_{A_{L 2}}(f p / H W) n_{i} \bar{u}_{i} d A+\iint_{A_{R C} \sigma_{i j} n_{j} \bar{u}_{i} d A}
\end{aligned}
$$

The solution to Equation (30) requires that the contact area $A_{R C}$ (i.e., the contact angles $\theta_{\mathrm{U}}$ and $\theta_{\mathrm{L}}$, Figure 4) be known. However, the contact angles $\theta_{\mathrm{U}}$ and $\theta_{\mathrm{L}}$ are as yet unknown; therefore, these angles must be determined before solutions for $u_{k}$ can be obtained. The following procedure is suitable for calculating $\theta_{\mathrm{U}}$ and $\theta_{\mathrm{L}}$ :

Values of $\theta_{\mathrm{U}}$ and $\theta_{\mathrm{L}}$ (designated as $\theta_{\mathrm{U}}^{\mathrm{a}}$ and $\theta_{\mathrm{L}}^{\mathrm{a}}$ ) are assumed such that these values are greater than $\pi / 2$. The normal stresses along the contact surfaces bounded by the $\operatorname{arcs} \theta^{\mathrm{a}}{ }_{\mathrm{U}}$ and $\theta_{\mathrm{L}}^{\mathrm{a}}$ are calculated. For contact angles greater than the actual contact angles compressive stresses become tensile (stress reversal) as illustrated in Figure 5. The angles $\theta_{\mathrm{U}}^{\mathrm{a}}$ and $\theta^{\mathrm{a}}{ }_{\mathrm{l}}$ are then decreased slightly, and the stresses are calculated again. This procedure is repeated until no reversal in sign of the normal stresses occurs along the arcs, 0 to $\theta_{U}$ and 0 to $\theta_{\mathrm{L}}$ (i.e., both contact surfaces are in compression). These values, $\theta_{\mathrm{U}}$ and $\theta_{\mathrm{L}}$, are taken to be the contact angles.

\section{METHOD OF SOLUTION}

Solutions to Equations (25) and (30) must be obtained by numerical means. In this investigation a finite element method of solution was used. The calculation procedures for laminates containing a single hole were given in 

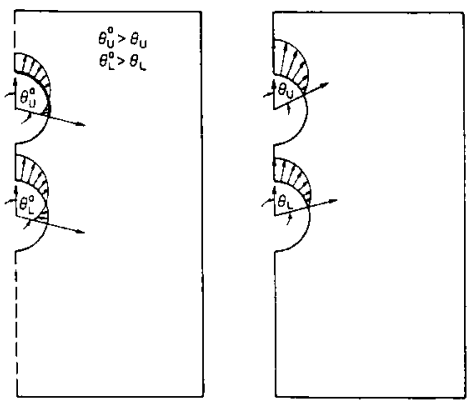

Figure 5. Illustration of the reversal of the normal stresses when the assumed contact angles $\theta^{\circ}{ }_{U}$ and $\theta^{a}{ }_{L}$ are greater than the actual contact angles (left). No stress reversal occurs for the actual contact angles $\theta_{U}$ and $\theta_{L}$ (right).

References $[10,11]$. These procedures were extended to laminates containing two pin-loaded holes either in parallel or in series. Details of the procedures pertaining to laminates with two holes are not given here but may be found in Reference [22].

A "user friendly" computer code (designated as "BOLT") was developed suitable for performing the calculations. The input parameters required by the code and the output provided by the code are discussed in Section 6 . The "BOLT" code may be obtained from G.S.S.

\section{PREDICTION OF FAILURE}

In order to determine the load at which a joint fails (failure load) and the mode of failure, the conditions for failure must be established. In this investigation the joint is taken to have failed when certain combined stresses have exceeded a prescribed limit in any of the plies along a chosen curve (denoted as the characteristic curve). The combined stress limit is evaluated using the failure criterion proposed by Yamada-Sun [28]. This failure prediction method was adopted here because it showed promising results for laminates containing a single pin-loaded hole $[10,11]$. Although the method was explained in References [10,11], it is summarized below in order to bring together the entire solution procedure.

\section{Failure Criterion}

In this investigation, the Yamada-Sun failure criterion was adopted [28]. This criterion is based on the assumption that just prior to failure of the laminate, every ply has failed due to cracks along the fibers. This criterion states that failure occurs when the following condition is met in any one of the plies

$$
\left(\sigma_{x} / X\right)^{2}+\left(\sigma_{x y} / S\right)^{2}=e^{2}, \quad \begin{cases}e<1 & \text { no failure } \\ e \geqslant 1 & \text { failure }\end{cases}
$$


As indicated in Equation (31) failure occurs when $e$ is equal to or greater than unity. In the above equation, $\sigma_{x}$ and $\sigma_{x y}$ are the longitudinal and shear stresses in a ply, respectively ( $x$ and $y$ being the coordinates parallel and normal to the fibers in the ply). $S$ is the rail shear strength of a symmetric, cross ply laminate $[0 / 90]_{5} . X$ is either the longitudinal tensile strength or the longitudinal compressive strength of a single ply. The tensile strength $\left(X=X_{t}\right)$ is used when the stress $\sigma_{x}$ is tensile. The compressive strength $\left(X=X_{c}\right)$ is used when $\sigma_{x}$ is compressive.

\section{Failure Hypothesis-Characteristic Curve}

The hypothesis is proposed that failure occurs when, in any one of the plies, the combined stresses satisfy an appropriately-chosen failure criterion at any point on a characteristic curve. The characteristic curve (Figure 6) is specified by the expression

$$
r_{\mathrm{c}}(\theta)=D / 2+R_{t}+\left(R_{\mathrm{c}}-R_{\mathrm{t}}\right) \cos \theta
$$

The angle $\theta$, measured clockwise from the $\mathrm{x}_{2}$ axis, may range in value from $-\pi / 2$ to $\pi / 2$. $R_{\mathrm{z}}$ and $R_{\mathrm{c}}$ are referred to as the characteristic lengths for tension and compression. These parameters must be determined experimentally, as is discussed in a companion article [29].

In this investigation, the characteristic curve is used together with the Yamada-Sun failure criterion. Accordingly, failure occurs when the parameter $e$ is equal to, or is greater than unity at any point on the characteristic curve

$$
\left.\begin{array}{ll}
\text { No failure } & e<1 \\
\text { Failure } & e \geqslant 1
\end{array}\right\} \text { at } r=r_{\mathrm{c}}
$$

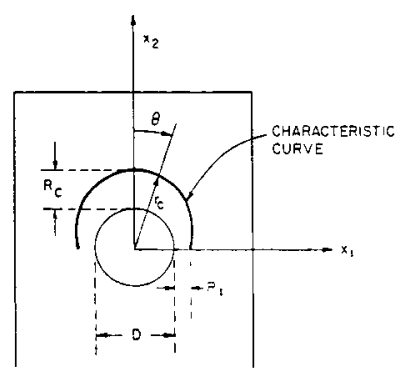

Figure 6. Description of the characteristic curve. 


\section{Solution Procedure}

Whether or not a joint fails under a given condition is determined as follows. For a given load

a) The components of strain $\varepsilon_{11}, \varepsilon_{22}$ and $\varepsilon_{12}$ are calculated.

b) The longitudinal and shear stresses in each ply are calculated using Equation (16).

c) The parameter $e$ is calculated (Equation 31) along the characteristic curve. Note that there is a characteristic curve around each hole; i.e. for two holes there are two characteristic curves.

d) If e equals or exceeds the value of unity $(e \geqslant l)$ in any ply along the characteristic curve (or curves) the joint is taken to have failed.

The procedure outlined above is used to predict whether or not failure occurs under a given load. Due to the assumption of a linear stress-strain relationship, the calculated stresses are linearly proportional to the applied load $P$. This fact, together with Yamada-Sun failure criterion (Equation 31) gives

$$
P \sim e
$$

This relationship is utilized to determine the maximum load $\left(\mathrm{P}_{\max }\right)$ which can be imposed on the joint. For a given load $\mathrm{P}$, values of $e$ are calculated on the characteristic curve, as discussed above (points a-d). Note again, that there are two characteristic curves when there are two holes. The highest value of $e\left(e_{o}\right)$ is then determined, and the maximum load is

$$
P_{\max }=P / e_{\text {。 }}
$$

The calculation procedure described in the foregoing also provides the location (angle $\left.\theta_{f}\right)$ at which $e$ first reaches the value of unity $(e=1)$ on the characteristic curve (Figure 7). A knowledge of $\theta_{f}$ provides an estimate of the mode of failure. Failure is taken to occur in the bearing mode when $\theta_{f}$ is small $\left(\theta_{f} \cong 0^{\circ}\right)$. Failure is taken to be due to shearout when $\theta_{f} \cong 45^{\circ}$. Failure is taken to be caused by tension when $\theta_{f} \cong 90^{\circ}$. In summary,

$$
\begin{aligned}
& -15^{\circ} \leqslant \theta_{f} \leqslant 15^{\circ} \text { bearing mode } \\
& 30^{\circ} \leqslant \theta_{f} \leqslant 60^{\circ} \text { shearout mode } \\
& 75^{\circ} \leqslant \theta_{f} \leqslant 90^{\circ} \text { tension mode }
\end{aligned}
$$

At intermediate values of $\theta_{f}$, failure may be caused by a combination of these modes.

\section{INPUT-OUTPUT PARAMETERS}

The failure analysis described in the previous section was coupled with the stress analysis and was included in the "Bolt" computer code. Thus, in addi- 


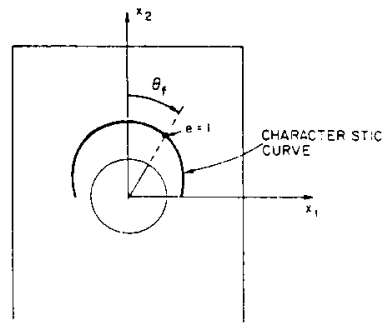

Figure 7. Location of failure $(e=1)$ along the characteristic curve.

tion to the stresses, the code also calculates the failure load and the failure mode. A list of the input parameters required for the solution of problems is given in Table 1. Material properties are given in Table 2.

\section{EXPERIMENTAL VALIDATION OF THE MODEL}

Experiments were performed to generate data which can be used to evaluate the accuracy of the model. The experimental apparatus and procedure are described in the Appendix. Data were obtained with Fiberite T300/1034-C graphite/epoxy composites having different geometries and dif-

Table 1. Input parameters required by the computer code and the output provided by the code.

Input Parameters

1) Material Properties

a. Longitudinal and transverse Young's moduli; $E_{x}$ and $E_{y}$

b. Shear modulus, $\mathbf{G}_{x y}$

c. Poisson's ratio, $\mu_{x y}$

d. Longitudinal tensile and compressive ply strengths, $X_{t}$ and $X_{c}$.

e. Rail shear strength of a cross ply laminate $[0 / 90]_{s}, S$

f. Characteristic lengths, $R_{t}$ and $R_{c}$

2) Geometry
a. hole diameter, D
b. thickness, $\mathrm{H}$
c. width, W
d. length, $L$
e. edge distance, $E$
f. distance between two holes, $G$ (for two holes only)

3) Ply orientations

Output Parameters

1) Failure load

2) Failure mode 
Table 2. Properties of fiberite T300/1034 C graphite/epoxy composite.

\begin{tabular}{llc}
\hline Longitudinal Young's Modulus, $E_{\mathrm{x}}$ & $=21300000 \mathrm{psi}$ \\
Transverse Young's Modulus, $E_{\mathrm{y}}$ & $=1700000 \mathrm{psi}$ \\
Shear Modulus, $\mathrm{G}_{\mathrm{xy}}$ & $=897000 \mathrm{psi}$ \\
Poisson's Ratio $\mu_{\mathrm{xy}}$ & $=0.3$ \\
Longitudinal Tensile Strength, $\mathrm{X}_{\mathrm{t}}$ & $=251000 \mathrm{psi}$ \\
Longitudinal Compressive Strength, $\mathrm{X}_{\mathrm{c}}$ & $=200000 \mathrm{psi}$ \\
Rail Shear Strength, $S$ & $=19400 \mathrm{psi}$ \\
Characteristic Length in Tension, $\mathrm{R}_{\mathrm{t}}$ & $=0.018 \mathrm{in}$ \\
Characteristic Length in Compression, $\mathrm{R}_{\mathrm{c}}$ & $=0.07 \mathrm{in}$ \\
\hline
\end{tabular}

ferent ply orientations. The failure strengths and the failure modes were measured with composites containing either one pin-loaded hole or two pinloaded holes in parallel, or two pin-loaded holes in series. The experimental results are presented in Figures 8 through 15. The data are tabulated in Reference [22].

To facilitate comparisons between the data and the results of the model, the ordinates in these figures represent the bearing strength $P_{B}$. For laminates with a single hole or with two holes in series, the bearing strength is expressed as $P_{B}=P / D H$. For laminates containing two holes in parallel, the bearing strength is taken as $P_{B}=P / 2 D H . P$ is the failure load and DH represents the cross sectional area of the hole. In Figures 8-15 the measured bearing strengths and failure modes are represented by different symbols.

The bearing strengths and failure modes were also calculated using the model. The numerical calculations were performed using the material properties listed in Table 2. The numerical results are included in these figures. The calculated bearing strengths are given by solid lines. The calculated failure modes were not identified separately as long as they were the same as those given by the data. In those cases where the calculated failure model differed from the data, the calculated failure mode is identified by the letters T, B, or $S$, next to the corresponding data point. These letters represent failure in tension, bearing, and shearout modes.

As indicated in Figures 8-15, for $\left[(0 / \pm 45 / 90)_{3}\right]_{\mathrm{s}}$ and $\left[\left(90_{2} / \pm 60 / \pm 30\right)_{2}\right]_{\mathrm{s}}$ laminates the calculated failure strengths agree with the data within 10 percent to 30 percent. The specimen geometry (hole diameter, edge distance, and width) has little effect on the accuracy of the model.

For cross-ply laminates $\left([0 / 90]_{\mathrm{s}}\right.$ and $\left.[ \pm 45]_{\mathrm{s}}\right)$ the difference between the calculated bearing strengths and the data ranges from about 10 to 40 percent. The accuracy is better for smaller holes (10 percent for $D=1 / 8$ in) and decreases as the hole size increases. The differences between the calculated and measured bearing strengths become about 40 percent for $1 / 2$ in diameter holes. In all cases, the calculated values are conservative and underestimate the actual bearing strengths. The reason for the lower accuracy of the model 


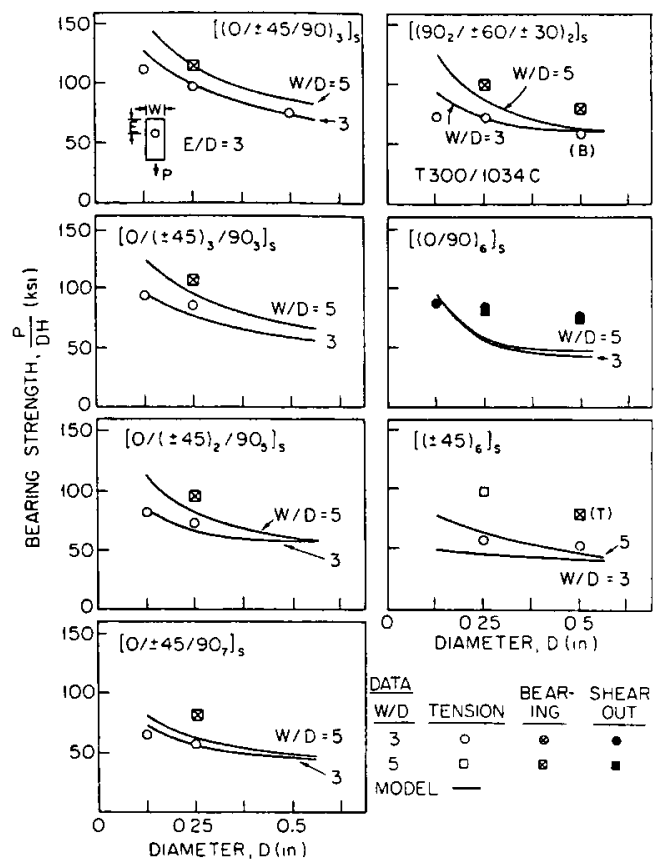

Figure 8. Bearing strengths of fiberite $7300 / 1034$ C laminates containing a single loaded hole. Comparisons between the data and the results of the model. The failure modes calculated by the model are the same as those of the data unless indicated by a letter in parentheses next to the data point.

for cross-ply laminates is most likely due to the assumption that the shear stress is linearly proportional to the shear strain. Since shear stresses are important in determining the failure strengths of cross-ply laminates [22,29] the use of nonlinear shear stress-strain relationships improve the accuracy of the model for such laminates [33].

The results in Figures 8-15 show that the model predicts the failure mode with good accuracy. Of the 83 specimen configurations tested, the model failed to predict accurately the failure mode only in 9 cases-these cases being indicated by the letters T, B, or S, in Figures 8-15. In 3 of those cases where the model gave different failure modes than the data, the data were ambiguous. Failure, in fact, may have occurred by a combination of two different modes.

The results discussed in the foregoing, and represented in Figures 8-15, show that the model provides the failure strengths and failure modes of loaded holes with reasonable accuracy. The accuracy of the present model could be improved further if, instead of the average values of $S, R_{1}$ and $R_{c}$, the values corresponding to the specific geometry and laminate configuration were used in the calculations.

It is worthwhile to compare the accuracy of the present model with the ac- 


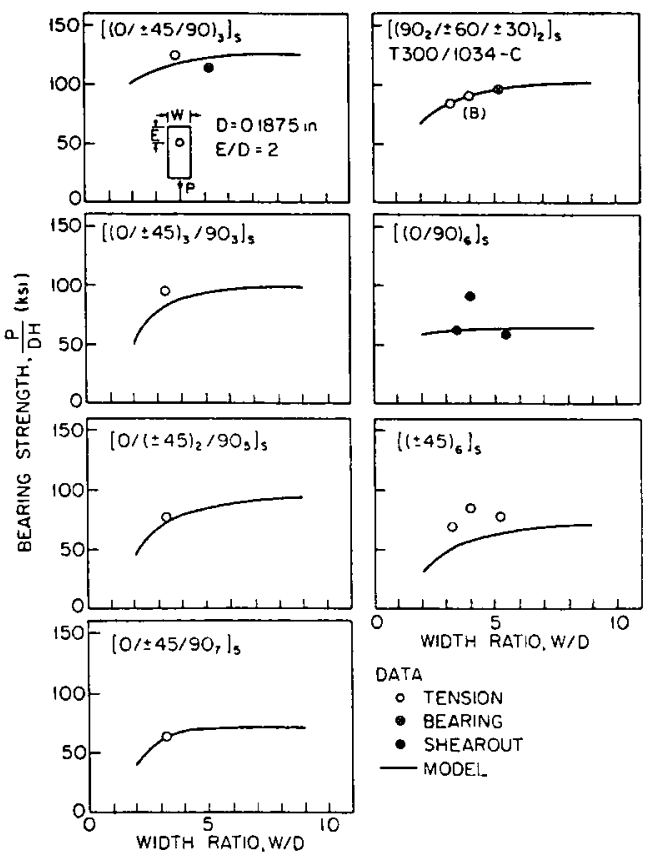

Figure 9. Bearing strengths of fiberite $T 300 / 1034 \mathrm{C}$ laminates containing a single loaded hole. Comparisons between the data and the results of the model. The failure modes calculated by the mode/ are the same as those of the data unless indicated by a letter in parentheses next to the data point.

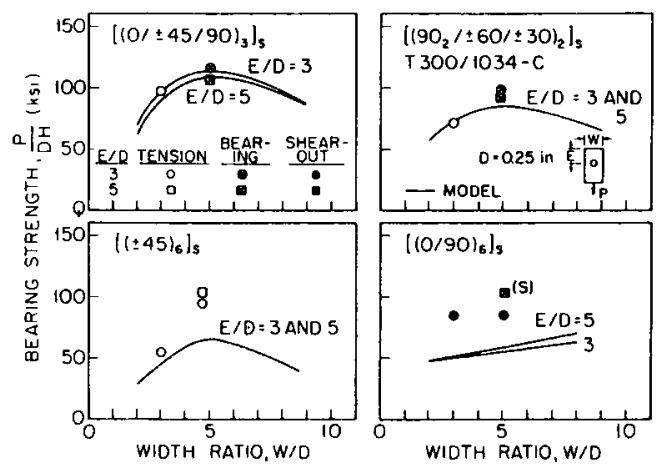

Figure 10. Bearing strengths of fiberite T300/1034-C laminates containing a single loaded hole. Comparisons between the data and the results of the model. The failure modes calculated by the model are the same as those of the data unless indicated by a letter in parentheses next to the data point. 

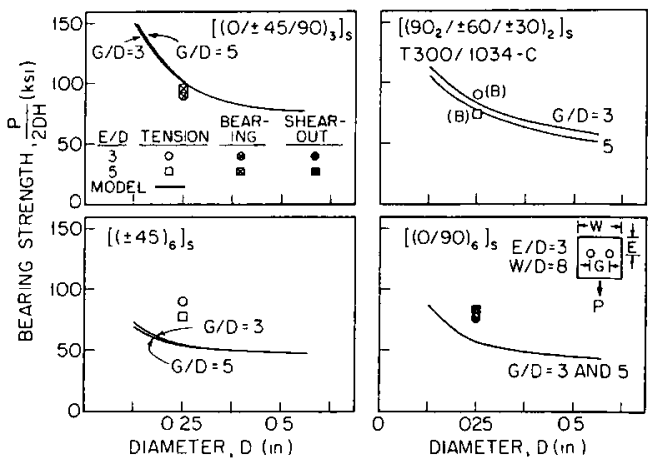

Figure 11. Bearing strengths of fiberite $7300 / 1034 \mathrm{C}$ laminates containing two loaded holes in parallel. Comparisons between the data and the results of the model. The failure modes calculated by the model are the same as those of the data unless indicated by a letter in parentheses next to the data point.
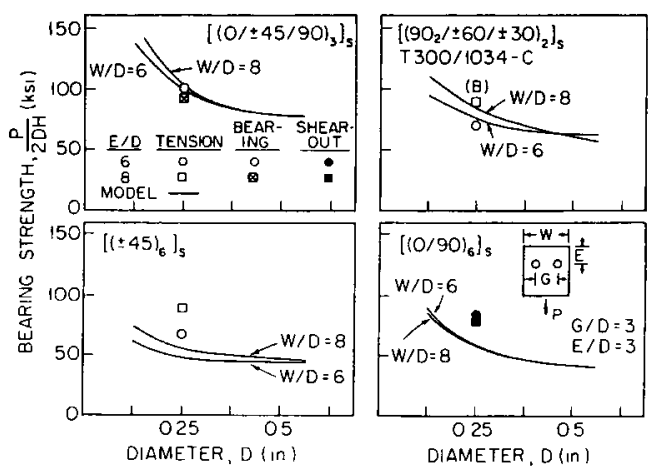

Figure 12. Bearing strengths of fiberite $7300 / 1034-C$ laminates containing two loaded holes in parallel. Comparisons between the data and the results of the model. The failure modes calculated by the model are the same as those of the data unless indicated by a letter in parentheses next to the data point.

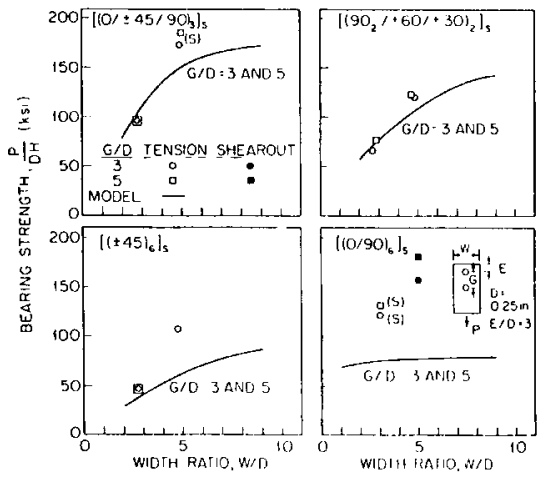

Figure 13. Bearing strengths of fiberite T300/1034-C laminates containing two loaded holes in series. Comparisons between the data and the results of the model. The failure modes calculated by the model are the same as those of the data unless indicated by a letter in parentheses next to the data point. 

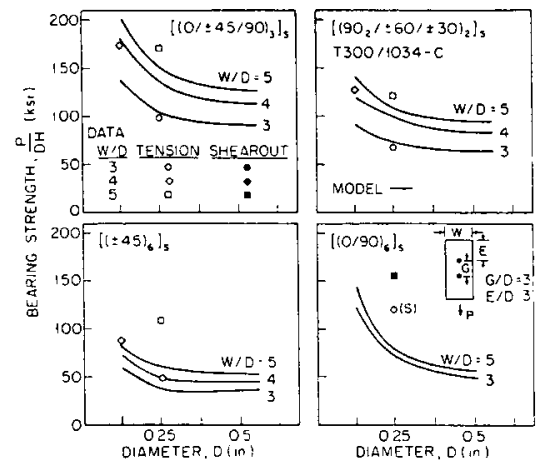

Figure 14. Bearing strengths of fiberite T300/1034-C laminates containing two loaded holes in series. Comparisons between the data and the results of the model. The failure modes calculated by the mode/ are the same as those of the data unless indicated by a letter in parentheses next to the data point.
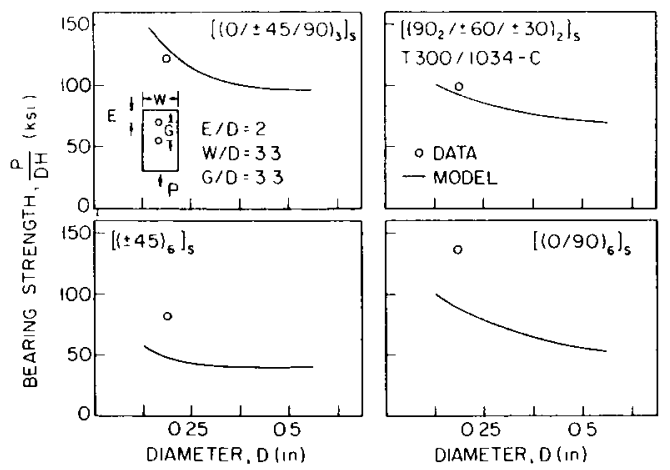

Figure 15. Bearing strengths of fiberite T300/1034-C laminates containing two loaded holes in series. Comparisons between the data and the results of the model. The failure modes calculated by the model are the same as those of the data.

curacy of the models developed by previous investigators. A summary of the accuracies of the various models is presented in Table 3.

The accuracy may depend on the geometry, ply orientation, and material properties. Therefore, the results in Table 3 should be viewed with some caution. Nevertheless, the numbers in this table provide an estimate of the magnitudes of errors in the different models. The present model appears to be more accurate than any of the other models.

Two points are worth noting: First, the models developed previously apply only to laminates containing a single hole. None of the models, except the present one, applies to laminates containing two holes. Second, of the existing models, only the present one and the one by Garbo and Ogonowski [6] 
Table 3. Approximate differences between experimental (P) and calculated $\left(P_{c}\right)$ fallure loads of laminate containing a single loaded hole.

The numbers indicate the maximum differences (in percent) for the indicated hole diameters and ply orientation.

\begin{tabular}{|c|c|c|c|c|c|c|c|}
\hline Investigator & Diameter & $1 / \pm 45 / 90]$ & $0 / \pm 60 / 9$ & $45 / 9$ & $1 \pm 46$ & {$[0 / 90]_{s}$} & {$[ \pm 45]$} \\
\hline $\begin{array}{l}\text { Present } \\
\text { T300/1034-C }\end{array}$ & $1 / 8-1 / 2$ & $10-20$ & $10-30$ & & & $10-40$ & $10-40$ \\
\hline $\begin{array}{l}\text { Agarwal [4] } \\
\text { SP286 }\end{array}$ & $3 / 16$ & 10 & & & 20 & 50 & 50 \\
\hline $\begin{array}{l}\text { Collings [9] } \\
\text { HTS/914, XAS/914 } \\
\text { HTS/HC } 3401\end{array}$ & $1 / 4$ & 20 & & 20 & & 20 & \\
\hline $\begin{array}{l}\text { Garbo [6] } \\
\text { AS/3501-6 }\end{array}$ & $1 / 4$ & 40 & & & & & \\
\hline $\begin{array}{l}\text { Hart-Smith [31] } \\
\text { T300/5208 }\end{array}$ & $1 / 4$ & 30 & & & & & \\
\hline $\begin{array}{l}\text { Pipes }[7,8] \\
\text { AS } / 3501-6\end{array}$ & $1 / 8,1 / 4,3 / 8$ & 20 & & & & & \\
\hline $\begin{array}{l}\text { Soni [5] } \\
\text { AS/3501-6, } \\
T 300 / 5208\end{array}$ & & 30 & & 50 & & & \\
\hline $\begin{array}{l}\text { Waszczak [1] } \\
\text { GR/EP,B/EP }\end{array}$ & & 50 & & 50 & & 50 & 50 \\
\hline
\end{tabular}

have been supplemented with "user friendly" computer codes. Therefore, presently, only these two models can be used readily. Furthermore, the Garbo and Ogonowski model yields the failure strength, but does not provide the mode of failure.

\section{CONCLUDING REMARKS}

The model and the corresponding computer code developed in this investigation can be used to determine the strength and the failure mode of composite laminates with one or two pin-loaded holes. As is shown in the next paper [32], the code can also be used to size composites containing more than two pin-loaded holes.

\section{ACKNOWLEDGEMENTS}

This work was supported by the Mechanics and Surface Interactions Branch, Nonmetallic Materials Division, Material Laboratory, Air Force Wright Aeronautical Laboratories, Wright-Patterson AFB, Ohio. Dr. S. W. Tsai was the project engineer. 


\section{REFERENCES}

1. Waszczak, J. P., and Cruse, T. A., "Failure Mode and Strength Predictions of Anisotropic Bolt Bearing Specimens," J. of Composite Materials, Vol. 5, pp. 421-425 (1971).

2. Oplinger, D. W., and Gandhi, D. R., "Stresses in Mechanically Fastened Orthotropic Laminates," Proceedings of the 2nd Conference on Fibrous Composites in Flight Vehicle Design, pp. 813-834 (May 1974).

3. Oplinger, D. W., and Gandhi, D. R., "Analytical Studies of Structural Performance in Mechanically Fastened Fiber-Reinforced Plates," in Proceedings of the Army Symposium on Solid Mechanics, 1974: The Role of Mechanics in Design-Structural Joints, Army Materials and Mechanics Research Center, 1974, AMMRC MS 74-8, pp. 211-242.

4. Agarwal, B. L., "Static Strength Prediction of Bolted Joint in Composite Material," $A I A A$ Journal, Vol. 18, pp. 1345-1375 (1980).

5. Soni, S. R., "Failure Analysis of Composite Laminates with a Fastener Hole," Joining of Composite Materials, ASTM STP 749, K. T. Kedward, Ed., Am. Soc. for Testing and Materials, pp. 145-164 (1981).

6. Garbo, S. P., and Ogonowski, J. M., "Effect of Variances and Manufacturing Tolerances on the Design Strength and Life of Mechanically Fastened Composite Joints," Flight Dynamics Laboratory, Air Force Wright Aeronautical Laboratories, Technical Report AFWAL-TR-81-3041, April, 1981.

7. York, J. L., Wilson, D. W., and Pipes, R. B., "Analysis of Tension Failure Mode in Composite Bolted Joints," J. of Reinforced Plastics and Composites, Vol. 1, pp. 141-153 (1982).

8. Wilson, D. W., and Pipes, R. B., "Analysis of the Shearout Failure Mode in Composite Bolted Joints," Proceedings of the lst International Conference on Composite Structures, Paisley College of Technology, Scotland, pp. 34-49 (1981).

9. Collings, T. A., "On the Bearing Strengths of CFRP Laminates," Composites, Vol. 13, pp. 242-252 (1982).

10. Chang, F. K., Scott, R. A., and Springer, G. S., "Strength of Mechanically Fastened Composite Joints," J. of Composite Materials, Vol. 16, pp. 470-493 (1982).

11. Chang, F. K., Scott, R. A., and Springer, G. S., "Strength of Mechanically Fastened Composite Joints," Air Force Wright Aeronautical Laboratories Technical Report AFWALTR-82-4095, July, 1982.

12. Wong, C. M. S., and Matthews, F. L., "A Finite Element Analysis of Single and Two-Hole Bolted Joints in Fibre Reinforced Plastic," J. of Composite Materials, Vol. 16, pp. 481-491 (1982).

13. Pagano, N. J., and Pipes, R. B., "The Influence of Stacking Sequence on Laminate Strength," J. of Composite Materials, Vol. 5, pp. 50-57 (1971).

14. Quinn, W. J., and Matthews, F. L., "The Effect of Stacking Sequence on the Pin-Bearing Strength in Glass Fibre Reinforced Plastic," J. of Composite Materials, Vol. 11, pp. 139-145 (1977).

15. Whitney, J. M., and Kim, R. Y., "Effect of Stacking Sequence on the Notched Strength of Laminated Composites," Composite Materials: Testing and Design (4th Conference), ASTM STP 617, pp. 229-242 (1977).

16. Daniel, I. M., Rowlands, R. E., and Whiteside, J. B., "Effects of Material and Stacking Sequence on the Behavior of Composite Plates with Holes," Experimental Mechanics, pp. 1-9 (1974).

17. Rybicke, E. F., and Schmueser, D. W., "Effect of Stacking and Lay-Up Angle on Free Edge Stresses Around a Hole in a Laminated Plate Under Tension," J. of Composite Materials, Vol. 12, pp. 300-313 (1978).

18. Collings, T. A., "The Strength of Bolted Joints in Multi-Directional CFRP Laminates," British Royal Aircraft Est., TR 75127, 1975. 
19. Stockdale, J. H., and Matthews, F. L., "The Effect of Clamping Pressure on Bolt Bearing Loads in Glass Fibre Reinforced Plastics," Composites, Vol. 7, pp. 34-38 (1976).

20. Fung, Y. C., Foundations of Solid Mechanics, Prentice-Hall, Inc., Englewood Cliffs, New Jersey, 1965.

21. Jones, R. M., Mechanics of Composite Materials, Scripta Book Company, Washington, D.C., 1975.

22. Chang, F. K., Scott, R. A., and Springer, G. S., "Strength of Bolted Joints in Laminated Composites," Air Force Wright Aeronautical Laboratories, Technical Report AFWALTR-84-4029, 1984.

23. Wilkinson, T. L., Rowlands, R. E., and Cook, R. D., "An Incremental Finite Element Determination of Stresses Around Loaded Holes in Wood Plates," J. of Composites and Structures, Vol. 14, pp. 123-128 (1981).

24. Hong, C.-S., "Stresses Around Pin-Loaded Hole in Finite Orthotropic Laminates," Transactions of the Japan Society for Composite Materials, Trans. JSCM, Vol. 6, pp. 50-55 (1980).

25. Rowlands, R. E., Rahman, M. U., Wilkinson, T. L., and Chiang, Y. I., "Single- and Multiple-Bolted Joints in Orthotropic Materials," Composites, Vol. 13, pp. 273-279 (1982).

26. Bickley, W., "The Distribution of Stress Round a Circular Hole in a Plate," Phil. Trans. Roy. Soc., A(London), Vol. 227, pp. 383-415 (1982).

27. De Jong, T., "Stress Around Pin-Loaded Holes in Elastically Orthotropic or Isotropic Plates," J. of Composite Materials, Vol. 11, pp. 313-331 (1977).

28. Yamada, S. E., and Sun, C. T., “Analysis of Laminate Strength and Its Distribution," J. of Composite Materials, Vol. 12, pp. 275-284 (1978).

29. Chang, F. K., Scott, R. A., and Springer, G. S., "The Effect of Laminate Configuration on Characteristic Lengths and Rail Shear Strength," J. of Composite Materials, Vol. 18, pp. 290-296 (1984).

30. Private Communication, Fiberite Company, Winona, Minnesota 55987.

31. Hart-Smith, L. T., "Bolted Joints in Graphite-Epoxy Composites," NASA-CR-144899, June, 1976.

32. Chang, F. K., Scott, R. A., and Springer, G. S., "Design of Composite Laminates Containing Pin Loaded Holes," J. of Composite Materials, Vol. 18, pp. 279-289 (1984).

33. Chang, F. K., Scott, R. A., and Springer, G. S., "Failure Strength of Nonlinearly Elastic Composite Laminates Containing a Pin Loaded Hole," J. of Composite Materials, Vol. 18, pp. 255-278 (1984).

\section{APPENDIX}

\section{Experimental Apparatus and Procedure}

The apparatus and procedure are described below. In addition, the procedure used to fabricate the specimens is described briefly.

The test fixture is shown in Figure 16. The top part of the fixture consisted of two 3 in wide and 5 in long steel plates ("main plates"). A 1.25 in diameter and 3.5 in long rod was inserted between these plates. The rod was fastened to the main plates by bolts. A 0.5 in diameter hole was drilled along the center line of each main plate, 1.5 in from the bottom edge. A 0.5 in dowel pin was inserted into this hole.

The bottom part of the fixture consisted of two 3 in wide and 5 in long "base plates." These plates were supported by the dowel pin. The material to 


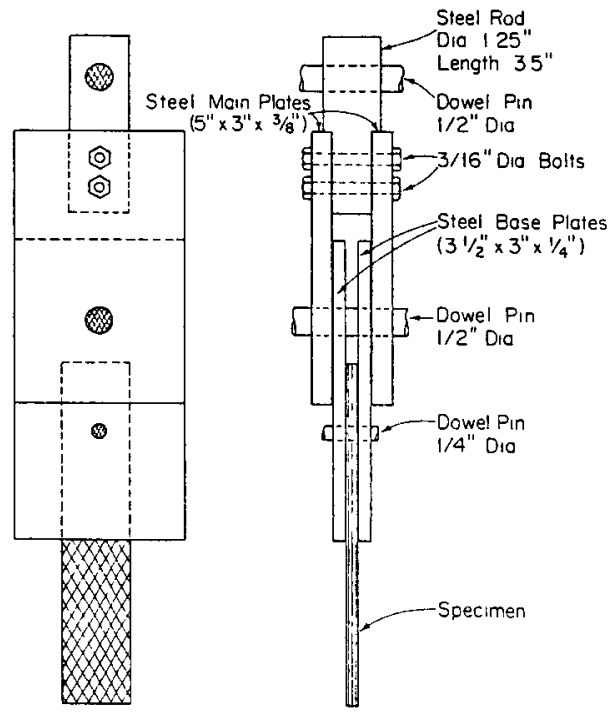

Figure 16. Fixture used in testing loaded holes (base plate geometry given in figure 17 and Table 4).

be tested was placed between the two base plates. A second 0.5 in diameter dowel pin was passed through the base plates and the laminate. In case of laminates with two holes, two 0.5 in diameter dowel pins were used.

In each test the same main plate and the same dowel pin were used. The dimensions of the base plates were different, depending upon the specimen configuration. The dimensions of the base plates are given in Figure 17 and Table 4.

A C clamp was placed around the base plates near the lower dowel pin and tightened by hand. The purpose of this clamp was to simulate the lateral force which would be provided by "finger-tight" bolts in the hole.
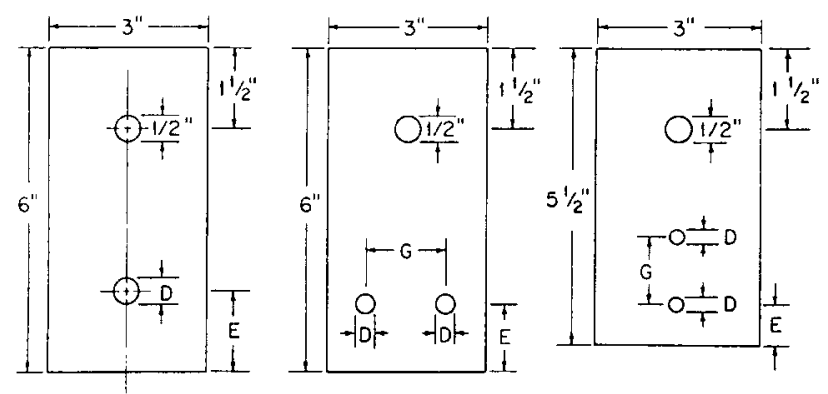

Figure 17. Base plates configurations (see Figure 16). Plate thickness $1 / 4$ in. The dimensions $G$, $D$, and $E$ are given in Table 4. 
Table 4. Dimensions of the base plates shown in Figures 16 and 17. All units in inches.

\begin{tabular}{clll}
\hline Single Hole & \multicolumn{1}{c}{ D } & G & E \\
Plate 1 & 0.5 & - & 1.5 \\
Plate 2 & 0.25 & - & 1.0 \\
Plate 3 & 0.1875 & - & 0.75 \\
Plate 4 & 0.125 & - & 0.5 \\
Two Holes in Parallel & & & \\
Plate 1 & 0.5 & 2.5 & 1.5 \\
Plate 2 & 0.5 & 1.5 & 1.5 \\
Plate 3 & 0.25 & 1.25 & 1.0 \\
Plate 4 & 0.25 & 0.75 & 1.0 \\
Two Holes in Series & & & \\
Plate 1 & & 1.25 & 0.75 \\
Plate 2 & 0.25 & 0.75 & 0.75 \\
Plate 3 & 0.25 & 0.625 & 0.5 \\
Plate 4 & 0.1875 & 0.375 & 0.5 \\
\hline
\end{tabular}

During the tests the rod protruding from the main plates was inserted into the upper grips, and the laminate was inserted into the lower grips of a mechanical testing machine. A tensile load was applied by the machine and the ultimate tensile strength was recorded. After the test, each specimen was inspected and the mode of failure was determined.

\section{Specimen Preparation}

The laminates were constructed from Fiberite T300/1034-C prepreg tape. The panels were cured in an autoclave [30]. The test specimens were cut by a diamond saw. The holes were drilled with solid carbide drills for hole diameters less than one-half inch and by carbide tip drills for $1 / 2$ in diameter holes. The nominal sizes of holes were $0.125 \mathrm{in}, 0.1875 \mathrm{in}, 0.25 \mathrm{in}$, and $0.5 \mathrm{in}$. The nominal size of the dowel pins were the same. To provide a close fit, each dowel pin was dressed down by about 0.001 in. 